\title{
Correction to: Pathophysiologic Approach to Pain Therapy for Complex Pain Entities: A Narrative Review
}

Martina Rekatsina - Antonella Paladini - Alba Piroli - Panagiotis Zis ·

Joseph V. Pergolizzi · Giustino Varrassi (1)

Published online: January 31, 2020

(C) The Author(s) 2020

Correction to: Pain Ther

https://doi.org/10.1007/s40122-

019-00147-2

Figure 1 caption was processed and published incorrectly. The correct caption should read as follows:

The original article has been corrected.

The original article can be found online at https://doi. org/10.1007/s40122-019-00147-2.

M. Rekatsina

Department of Anaesthesia and Pain Management, King's College Hospital, London, UK

A. Paladini $\cdot$ A. Piroli

Department of MESVA, University of L'Aquila,

67100 L'Aquila, Italy

P. Zis

Department of Neurology, Medical School,

University of Cyprus, Nicosia, Cyprus

J. V. Pergolizzi

Director of Analgesic Research Fellowship and COO,

NEMA Research Inc., Naples, FL 34108, USA

G. Varrassi $(\bowtie)$

Paolo Procacci Foundation, Via Tacito 7,

00193 Roma, Italy

e-mail: giuvarr@gmail.com

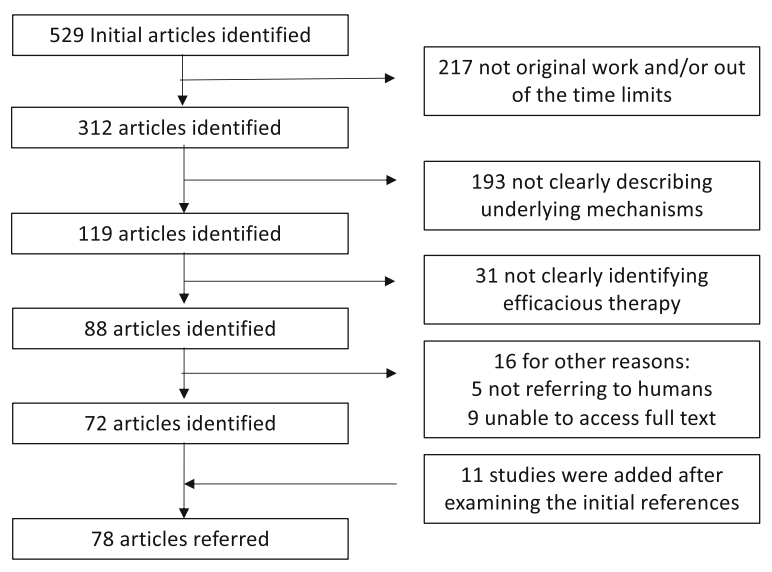

Fig. 1 Selection of referred papers

Open Access. This article is distributed under the terms of the Creative Commons Attribution-NonCommercial 4.0 International License (http://creativecommons.org/licenses/ by-nc/4.0/), which permits any noncommercial use, distribution, and reproduction in any medium, provided you give appropriate credit to the original author(s) and the source, provide a link to the Creative Commons license, and indicate if changes were made. 